\title{
molecules
}

ISSN 1420-3049

(C) 2007 by MDPI

www.mdpi.org/molecules

\author{
Full Paper
}

\section{Evaluation of the Antimicrobial and Antioxidant Activities of Origanum dictamnus Extracts before and after Encapsulation in Liposomes}

\author{
Olga Gortzi ${ }^{1}$, Stavros Lalas ${ }^{1, *}$, Ioanna Chinou ${ }^{2}$ and John Tsaknis ${ }^{3}$ \\ ${ }^{1}$ Department of Food Technology, Technological Educational Institution (T.E.I.) of Larissa, (Karditsa \\ Annex), Terma N. Temponera str., GR-43100, Karditsa, Greece; E-mail: ogortzi@teilar.gr \\ 2 Department of Pharmacy, Division of Pharmacognosy, Chemistry of Natural products, University of \\ Athens, Panepistimiopolis Zografou, GR-15771, Athens, Greece; E-mail: ichinou@pharm.uoa.gr \\ 3 Department of Food Technology, Technological Educational Institution (T.E.I.) of Athens, Ag. \\ Spyridonos str., GR-12210, Egaleo, Athens, Greece; E-mail: jtsaknis@teiath.gr
}

* Author to whom correspondence should be addressed; E-mail: slalas@teilar.gr; Tel.: (+30)-24410-76454, Fax.: (+30)-24410-41080

Received: 22 March 2007; in revised form: 25 April 2007 / Accepted: 1 May 2007 / Published: 2 May 2006

\begin{abstract}
The antioxidant and antimicrobial activity of methanol or dichloromethane extracts of $O$. dictamnus, produced from wild and organic cultivated specimens, were determined. The Rancimat and malondialdehyde (MDA) by HPLC methods were used to measure the antioxidant action, in comparison with that of the common commercial antioxidants butylated hydroxytoluene (BHT) and $\alpha$-tocopherol. The extracts that presented high antioxidant activity were encapsulated in liposomes and their antioxidant action was again estimated using differential scanning calorimetry (DSC). Thermaloxidative decomposition of the samples (pure liposomes and encapsulated extracts) and the modification of the main transition temperature for the lipid mixture and the splitting of the calorimetric peak in the presence of the antioxidants were also studied by the DSC method. All extracts showed antioxidant and antimicrobial activities. Their action proved superior to $\alpha$-tocopherol. The methanol extract of organic cultivated O. dictamnus (240 ppm) showed higher activity than butylated hydroxytoluene. After encapsulation in liposomes the antioxidant as well as antimicrobial activities proved to be higher than those of the same extracts in pure form.
\end{abstract}


Keywords: Origanum dictamnus, liposomes, antimicrobial activity, antioxidant activity, DSC.

\section{Introduction}

Food preservation methods typically involve the use of heat, refrigeration, freezing, concentration, dehydration, irradiation, $\mathrm{pH}$ control, chemical preservatives, and packaging applied to produce various degrees of preservation in accordance with the differing use patterns and shelf-life needs of unique products. Chemical preservatives and similar substances include antimicrobials, enzyme inhibitors and antioxidants. Since, consumers' preferences favor natural substances instead of synthetic ones there is an increased interest in research for new "natural" products of plant origin. Unfortunately, most phytochemicals are biologically unstable, poorly soluble in water and distribute poorly to target sites. The ability of liposomes to help overcome the problem of reduced solubility in lipids of many plant extracts is very important. Additionally, extracts encapsulated in liposomes possess new physicochemical characteristics and bioactivity which can enhance the extract's original activity and become effective carriers for nutritionally valuable ingredients [13]. However, the use of already discovered and tested natural compounds should not be neglected due to recent research [14] in the field of encapsulation (i.e. in liposomes).

The majority of microencapulation techniques currently used in the food industry are based on biopolymer matrices composed of sugars, starches, gums, proteins, synthetics, dextrins and alginates nevertheless, liposomes have recently begun to gain in importance. In recent studies [13, 14], nanoencapsulation generally improved the antimicrobial activity of compounds and maintained the stability of antimicrobials over prolonged periods of time, thereby improving the safety of fresh and processed food products. Development of release-on-demand, targeted nanoencapsulation systems has implications beyond the delivery of bioactive compounds and may lead to the development of new invivo intracellular and cell membrane biosensors with the ability to monitor growth and/or kill of pathogens and spoilage organisms in real time [4]. Based on results of studies of liposomes for pharmaceutical and medical uses, food scientists have begun to utilize liposomes for controlled delivery of functional components such as proteins and enzymes, vitamins and flavors in various food applications [31].

Origanum dictamnus L., also known as Dittany (not to be confused with White Dittany, Dictamnus albus), is a rare endemic plant that grows wild on the rocky mountains of the island of Crete (South Greece). It is widely known from the time of Aristotle for its healing properties on wounds and for treatment of difficult labor in women [33].

Flavonoids and coumarins, two of the major categories of phenolic compounds in plants, have been previously discovered in the polar extracts of the plant [27, 28]. Previous studies concerning the antioxidant properties of Dittany extracts have shown that the ethanol extract is equally active to $\alpha$ tocopherol [7, 19]. Couladis et al. [7] and Moller et al. [19] (during the evaluation of antioxidant activity of $O$. dictamnus extracts, produced with solvents of various polarities, using electron spin resonance spectrometry and oxygen depletion in methyl linoleate emulsion to determine their 
efficiencies as scavengers of free radicals and as chain-breaking antioxidants, respectively) proved that the aqueous extract of $O$. dictamnus was the most efficient scavenger of the hydroxyl radicals generated by the Fenton reaction, and also most efficient reducer of oxygen consumption, when initiated with methmyoglobin. The ethanol and acetone extracts showed less activity in both assays, while the methanol extract showed intermediate activity $[7,19]$. The high antioxidant efficiency of both water and methanol extracts is closely related to the high content of phenolic compounds in these extracts $[5,19]$ and since $O$. dictamnus is a traditionally consumed plant, the extract can be easily used as a natural preservative of food products in order to prevent oxidation and microbial spoilage [8].

The non polar extract of $O$. dictamnus has also proved to be a potential antioxidant. Specifically, in the non-saponified fraction of the hexane extract have been identified all four analogues of tocopherol ( $\alpha$-, $\beta$-, $\gamma$-, and $\delta$-tocopherol), with $\gamma$-tocopherols being in the higher concentration [15].

In this work, we evaluated the antioxidant and antimicrobial activity of extracts of Origanum dictamnus (wild or cultivated, both indigenous in Greece) and compared them with known synthetic (BHT) or natural ( $\alpha$-tocopherol) antioxidants and antimicrobial agents (netilmicin and intraconazole). The extracts were also encapsulated in liposomes and their modified activities were determined. Liposomes were used because, due to their unique properties, are able to enhance the performance of products by increasing ingredient solubility (easier incorporation of water soluble compounds into oil based products), improving bioavailability and in vitro stability [13, 14].

\section{Results and Discussion}

The antioxidant action of Origanum dictamnus pure extracts was initially determined using the Rancimat stability test, oxidative stability by DSC and MDA by HPLC. Results are presented in Figures 1 and 2.

Figure 1. Protection Factors of Origanum dictamnus pure extracts in stripped sunflower oil.

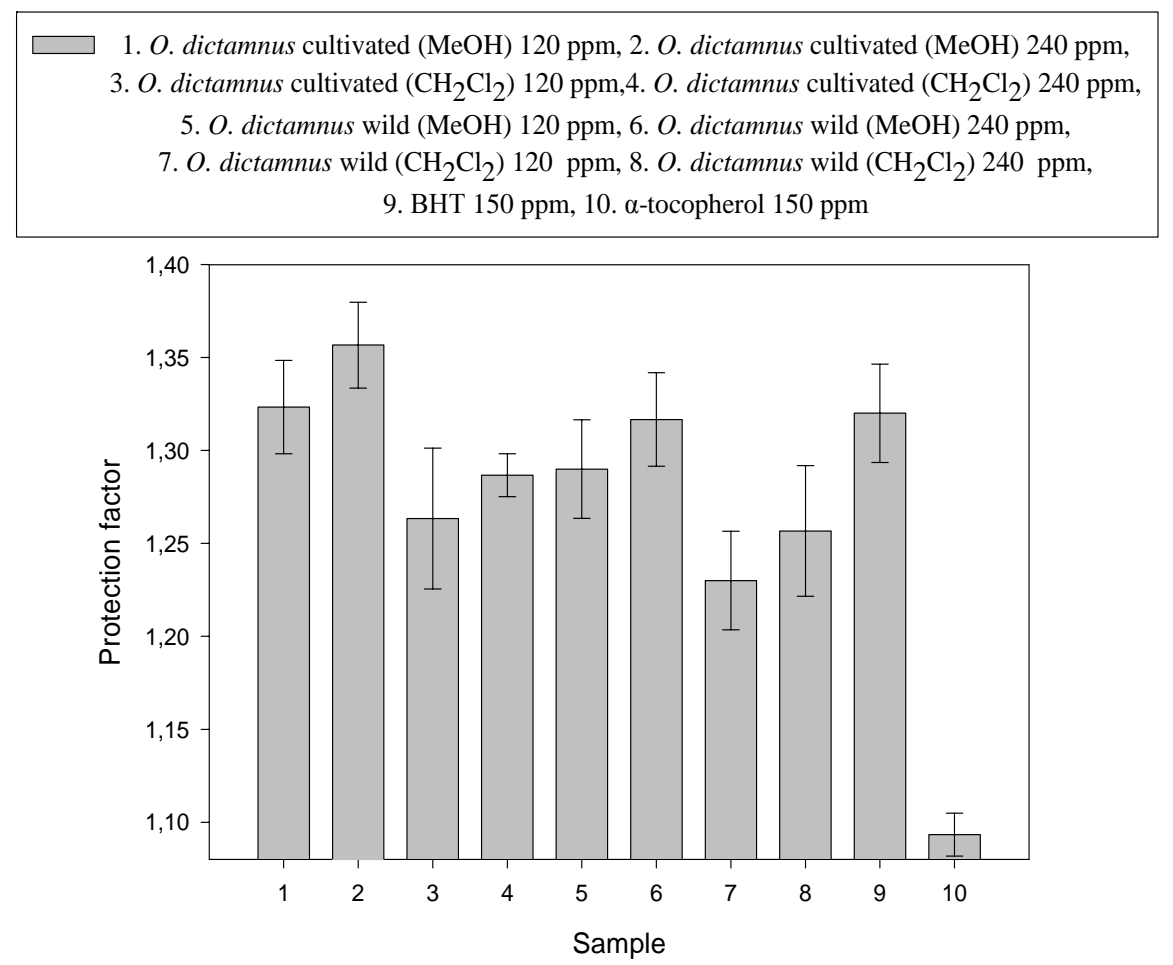


All the extracts showed antioxidant activity. The cultivated organic Dittany extract showed stronger antioxidant activity than the wild type and the methanol extracts were stronger (significant at $\mathrm{P}<0.05$ ) than the dichloromethane ones. The antioxidant activities were compared with those of the common commercial antioxidants BHT and $\alpha$-tocopherol. Specifically, the methanol extract of organic cultivated $O$. dictamnus at a concentration of $240 \mathrm{ppm}$ showed significantly higher activity $(\mathrm{P}<0.05)$ than that of BHT, while those of cultivated Dittany (120 ppm) and wild specimen (240 ppm) showed no significant difference $(\mathrm{P}<0.05)$ compared to BHT. All the other extracts showed lower antioxidant activity than BHT, but superior activity (significant at $\mathrm{P}<0.05$ ) than $\alpha$-tocopherol. The antioxidant protective ability of the polar methanol extracts can be attributed to their high phenolic content, consisting mainly from flavonoids and coumarins [5, 19, 27, 28], while the antioxidant properties of the non polar hexane extract are attributable to the contained tocopherols [15].

Figure 2. Malondialdehyde (MDA) concentration in stripped sunflower oil with various concentrations of Origanum dictamnus pure extracts (100 and 150 ppm) after application of the UV accelerated method.
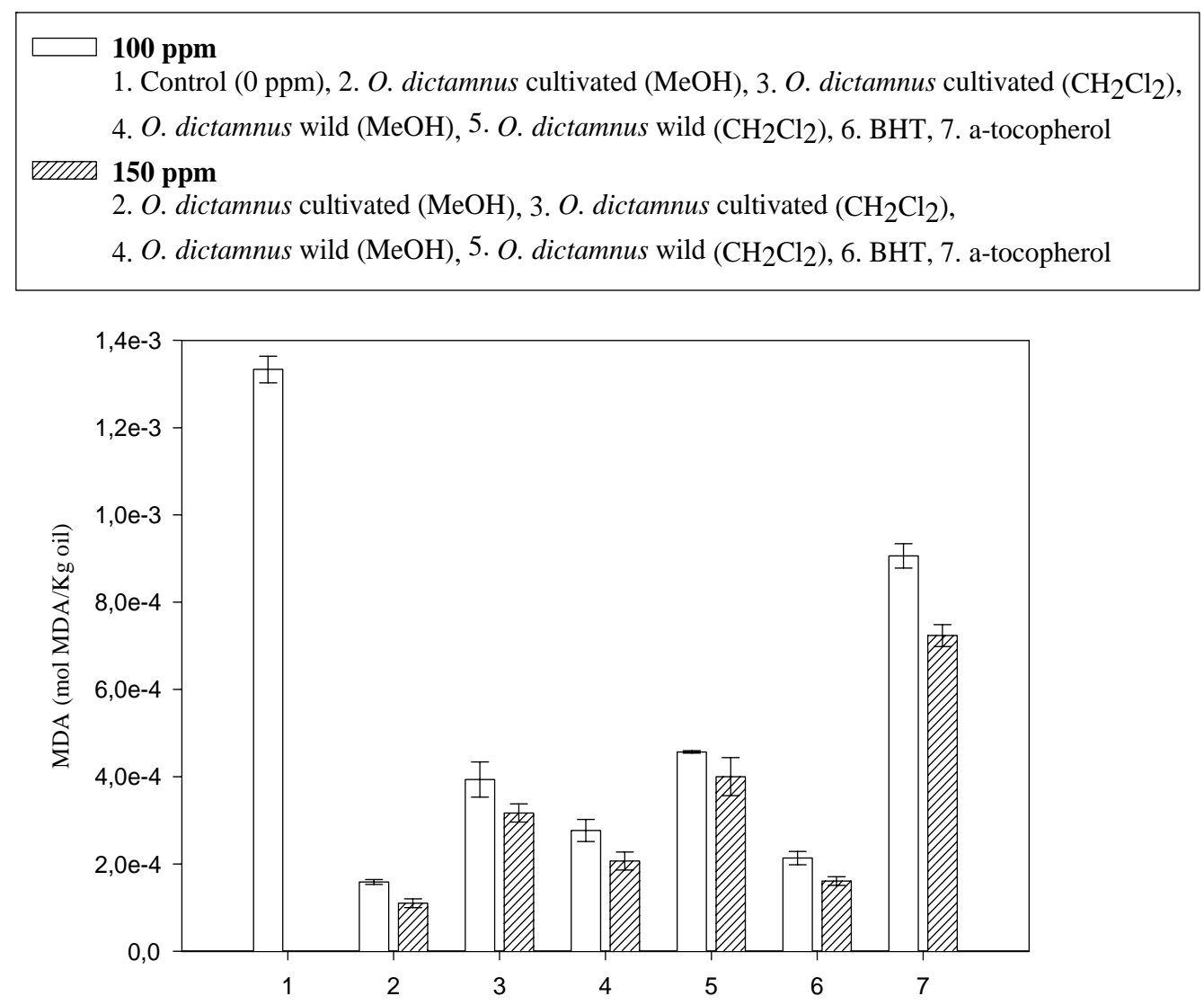

Wild plants and cultivated species exhibit great variation in secondary metabolites contents, as well as their biological activities, due to the growth environment (i.e. soil type, nutrients, topographic, salinity, drought, allelochemicals) and genetic differences among species [6]. As indicated by Azaizeh et al. [2], fertilization regimes may alter antioxidant activity of cultivated medicinal plants when compared with that of wild ones, and the same authors proved that increasing the amount of fertilizer increased the antioxidant activity of the powders prepared from cultivated Teucrium polium. 
Figure 3. DSC oxidation (DSC-Heat flow/Time) of wild Origanum dictamnus pure extracts and encapsulated in liposomes.

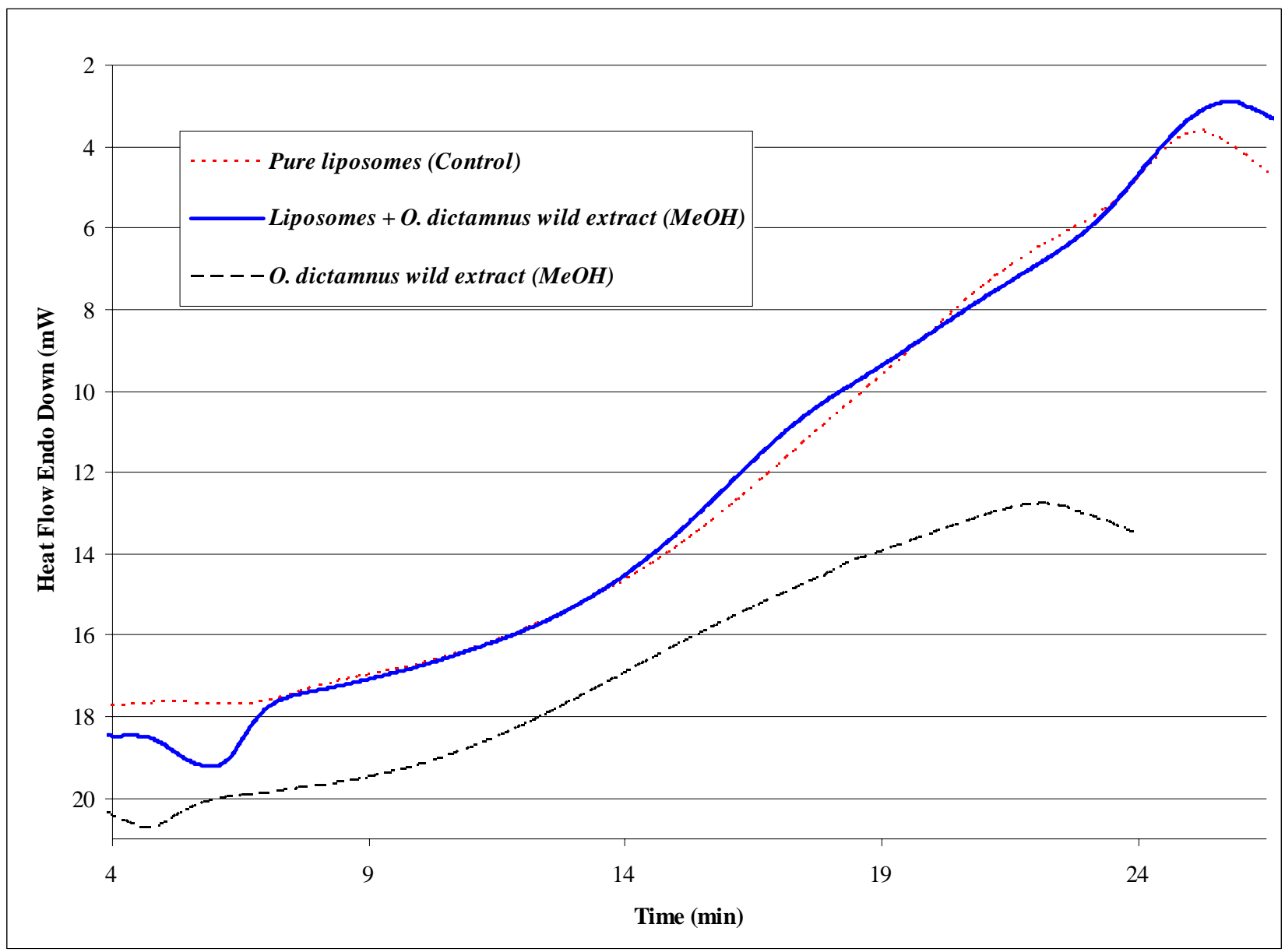

Auto-oxidation of fats, fatty acids and lipids is a well established exothermic process and thermal analysis methods are valuable for studying thermostability and themoxidation [18]. DSC is a good technique for determining the kinetic parameters of the non-inhibited and inhibited fatty acid oxidation. The extrapolated temperature of the start of the oxidation process is useful to evaluate antioxidant activity [18]. In Figures 3 and 4 the DSC curves of O. dictamnus methanol extracts and liposome dispersions in the absence and in the presence of extract are given. Thermal-oxidative decomposition of pure extracts and liposome preparations was studied. In comparison to the Rancimat method, DSC is concluded to be useful as a method employing milder conditions and shorter time and which can be applied for the evaluation of oxidative stability of samples containing volatile antioxidants and other lipid systems containing water $[13,36]$. An exothermic peak is observed in the 180 to $380{ }^{\circ} \mathrm{C}$ range (for cultivated specimen) or $400{ }^{\circ} \mathrm{C}$ (for wild specimen), related to the process of auto-oxidation of the samples. Using the curves, the onset temperature at which the auto-oxidation process begins is determined [18]. As seen in Figures 3 and 4, the addition of extract encapsulated in liposomes produced a more intense antioxidant action (significant at $\mathrm{P}<0.05$ ) than in pure form. At the same heating rate, the temperature of the start of the oxidation reaction is significantly $(\mathrm{P}<0.05)$ higher. The modified antioxidant action of extract resulting from its encapsulation was expected, since the complex (liposome membrane-fraction) possesses new physicochemical characteristics and 
bioactivity dependant on structure, size and z-potential of the preparation [13, 30]. Liposomes containing extracts were more stable than those that were extract-free. This may imply that lipophilic substances in the extracts used and phospholipids are packed regularly and tightly, conferring membrane rigidity and decreasing membrane permeability. The Rancimat and DSC assays are based on generation of volatiles and thermal release, respectively, indicating the onset of advanced oxidation (termination). The IP values obtained by DSC were significantly lower than those obtained by the Rancimat method. These results are in agreement with those reported by other researchers, who have suggested that these differences may have been due to a higher surface-to-volume ratio used in DSC. For the oxidation curves obtained by the Rancimat method and by DSC analysis it is generally accepted that, at the accelerated stage, the oxidation rate depends only on oxygen availability and temperature [36].

Figure 4. DSC oxidation (DSC-Heat flow/Time) of Origanum dictamnus cultivated pure extracts and encapsulated in liposomes.

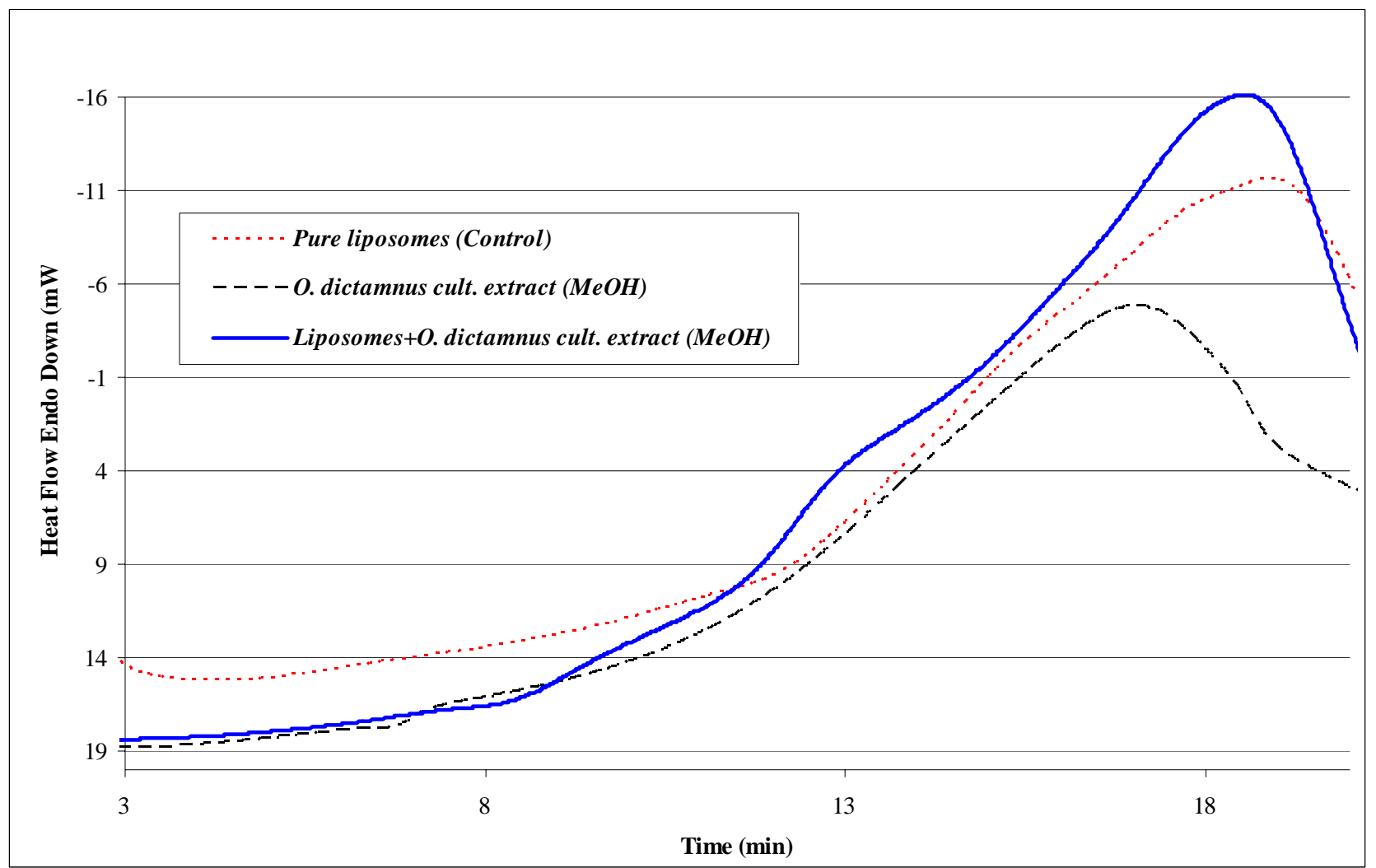

In spite of the different criteria considered to evaluate oxidative stability and the different experimental conditions applied (temperature and/or oxygen availability) the results obtained show that all three studied methods can predict the same relative oxidative stabilities. 
Table 1. Mean diameter $(\mathrm{nm})$ and z-potential $(\mathrm{mV})$ of the PhosphatidylcholineCholesterol (10:2 mg/mL) liposomes before and after cultivated O. dictamnus extract encapsulation.

\begin{tabular}{lll} 
Sample composition & Size (nm) & z-potential (mV) \\
\hline PC:C (no extract) & $250(15)$ & $-10.2(1.2)$ \\
\hline PC:C + O. dictamnus & $275(12)$ & $-10.5(0.4)$ \\
\hline
\end{tabular}

*Values are means of five subsequent determinations from three different samples. Standard Deviation is given in parenthesis.

Liposome size and surface charge were studied for extract-incorporating liposomes and empty liposomes for comparison. The characteristics of vesicles with different lipid compositions were compared (Table 1). The mean diameter of the vesicles ranged from $235 \mathrm{~nm}$ to $265 \mathrm{~nm}$ and the surface charge of all the vesicles was negative, ranging from -9.0 to $-11.4 \mathrm{mV}$. The incorporation of extract caused a significant change in the liposome surface structure and affected liposome size and zpotential. Indeed, the extract-incorporating liposomes were slightly larger (263-287 nm), a phenomenon also observed by other authors [13, 14, 17] which increases with the amount of substances incorporated in the lipid membrane, and they had a similar surface charge (-10.1 to -10.9 $\mathrm{mV}$ ). The extract composition seems to play a significant role in the way it can be packed in the lipid bilayer.

The methanolic extracts of $O$. dictamnus were also studied for their antimicrobial activity, both before and after encapsulation in liposomes (Table 2). Generally, all the plants of Lamiaceae family, which is well known for its phenolic compounds, have proven active against a variety of microorganisms [11, 22, 23, 26], but previous studies concerning the antimicrobial activity of $O$. dictamnus extract are however limited. A $70 \%$ water/methanol extract was active against Helicobacter pylori in an in vitro test [29]. In the present study, the methanol extract of $O$. dictamnus, for both wild and organic cultivated specimens, appeared active against all studied microorganisms (9$13 \mathrm{~mm}$ inhibition zones). In general, the gram negative bacterial spp. were the most resistant ones, as was Candida albicans among the tested fungi. The antimicrobial activity increased noticeably after the encapsulation of the methanol extract in liposomes. After the encapsulation, the exhibited antimicrobial activities appeared much stronger (significant at $\mathrm{P}<0.05$ ), mostly against the gram positive bacteria as well as against the food borne pathogen Listeria monocytogenes (12-13 mm inhibition zones). The empty liposomes, used as control, presented no activity towards the tested microorganisms. The antimicrobial properties of plant extracts have been of great interest in both academia and the food industry, due to their potential use as natural additives arising from a growing tendency to replace synthetic antimicrobial substances with natural ones [32]. Thanks to their strong antimicrobial activity, the extracts from the herbal parts of $O$. dictamnus used in our study could be considered a natural source that can be freely used in the food industry as a culinary herb. In particular, the dramatically increased antimicrobial activity after the encapsulation in liposomes could promote the use of the above mentioned extracts as potent preservatives and conservation agents, not only in food industry but also in cosmetics and medical preparations [13]. Applications of this technique have increased in the food industry since the encapsulated materials can be protect from moisture, heat or 
other extreme conditions, thus enhancing their stability and maintaining viability [12]. The liposomal forms promoted effective interaction between bacteria and bioactive compound. Sachetelli et al. [24] proved that antibiotics in liposomes were able to overcome bacterial resistance related to the permeability barrier and enzymatic hydrolysis by a fusion process between liposomes and bacterial membranes.

There are several steps for improving the bioavailability of dietary supplements including: enhancement of biological stability including solubility, improvement the cellular transport and release of the active component inside the cell [25]. Various methods exist to release the ingredients from capsules. Release can be site-specific, state-specific or signaled by changes in $\mathrm{pH}$, temperature, irradiation or osmotic shock.

Table 2. Antimicrobial activities (measured as inhibition zone in $\mathrm{mm}$ ) of cultivated and wild Origanum dictamnus methanol extracts before and after encapsulation in phosphatidylcholine-cholesterol liposomes (10:2 mg/mL).

\begin{tabular}{lcccccc}
\cline { 2 - 6 } Microbial spp. & $\begin{array}{l}\text { O. } \\
\text { dictamnus } \\
\text { wild }\end{array}$ & $\begin{array}{l}\text { Liposomes }+ \\
\text { O. dictamnus } \\
\text { wild }\end{array}$ & $\begin{array}{l}\text { O. dictamnus } \\
\text { cultivated }\end{array}$ & $\begin{array}{l}\text { Liposomes + } \\
\text { O. dictamnus } \\
\text { cultivated }\end{array}$ & Netilmicin & Intraconazole \\
\hline S. aureus & $12^{\mathrm{a}}(0.1)$ & $14(0.3)$ & $13(0.2)$ & $15(0.2)$ & $21(0.4)$ & - \\
S. epidermidis & $12(0.2)$ & $15(0.3)$ & $12(0.1)$ & $15(0.4)$ & $25(0.4)$ & - \\
S. mutans & $12(0.1)$ & $15(0.1)$ & $12(0.2)$ & $15(0.2)$ & $24(0.3)$ & - \\
S. viridans & $12(0.1)$ & $15(0.2)$ & $12(0.1)$ & $16(0.1)$ & $25(0.1)$ & - \\
P. aeruginosa & $11(0.1)$ & $12(0.2)$ & $11(0.3)$ & $12(0.2)$ & $20(0.1)$ & - \\
E. cloacae & $10(0.1)$ & $11(0.2)$ & $11(0.1)$ & $12(0.1)$ & $23(0.1)$ & - \\
K. pneumoniae & $9(0.1)$ & $11(0.1)$ & $10(0.1)$ & $12(0.1)$ & $22(0.3)$ & - \\
E. coli & $9(0.2)$ & $9(0.1)$ & $9(0.2)$ & $10(0.2)$ & $24(0.2)$ & - \\
C. albicans & $9(0.1)$ & $10(0.1)$ & $9(0.1)$ & $10(0.2)$ & - & $20(0.3)$ \\
C. tropicalis & $10(0.1)$ & $13(0.2)$ & $11(0.2)$ & $14(0.2)$ & - & $22(0.3)$ \\
C. glabrata & $10(0.2)$ & $12(0.2)$ & $12(0.1)$ & $14(0.2)$ & - & $23(0.3)$ \\
L. monocytogenes & $9(0.2)$ & $12(0.2)$ & $10(0.1)$ & $13(0.1)$ & $22(0.3)$ & - \\
\hline
\end{tabular}

${ }^{a}$ Results are means of triplicate determinations. Standard deviation is given in parenthesis.

\section{Conclusions}

The present study has demonstrated the potential antioxidant and antimicrobial-food preservative ability of $O$. dictamnus. Use of this aromatic plant, commonly used as a spice in foods or as hot drink after boiling in water, is deemed feasible as it is considered safe. O. dictamnus are self-growing hardy plants, extremely tolerant to drought, which can easily grow on rocky, arid soils. The encapsulation in liposomes modified the activities of the extracts. Both, antimicrobial and antioxidant activity was improved and their commercial application in food preservation could therefore be considered. The goal should be to demonstrate the true potential for liposomes entrapped antimicrobial to improve the quality and safety of a wide variety of food products. However, further investigation should be carried 
out on the modified solubility of extract, as well as the rate of release of its antioxidant-antimicrobial components from liposomes especially in real foods.

\section{Experimental}

\section{General}

Aerial parts of the wild $O$. dictamnus specimen were collected from the island of Crete (Heracleum-Greece) by E. Kastrinakis on the summer of 2002, while the biologically cultivated specimen was a kind gift of G.S. Stivaktakis ("Knossos Aromatic Plants” company, also from the Heracleum region). The dried aerial parts were powdered and extracted with dichloromethane $\left(\mathrm{CH}_{2} \mathrm{Cl}_{2}\right)$ or methanol $(\mathrm{MeOH})$ at room temperature using the method described by Lalas and Tsaknis [34], and the extracts were concentrated under vacuum (rotary evaporator). The evaluation of the antioxidant activity was carried out using the Rancimat method, the determination of malondialdehyde by HPLC (after oxidation with the accelerated UV method) and differential scanning calorimetry (DSC).

\section{Evaluation of the antioxidant activity by the Rancimat method}

The method used was adapted from Gortzi et al. [14]. The antioxidant (pure extract in concentrations 120 and $240 \mathrm{ppm}$, BHT and $\alpha$-tocopherol both at $150 \mathrm{ppm}$ - Sigma Chemicals Company Ltd., St. Louis, USA) was accurately weighed into stripped sunflower oil (Elais S.A., Athens, Greece) prepared using the method described by Fuster et al. [10] and its action was determined using a Rancimat 679 (Metrohm LTD, Herisau, CH 9101, Switzerland), along with another sample of sunflower oil without antioxidant (control). One $\mathrm{mL}$ of the appropriate solvent ( $\mathrm{MeOH}$ or $\mathrm{CH}_{2} \mathrm{Cl}_{2}$ ) was added in order to dissolve the antioxidant. The conditions were set at $90{ }^{\circ} \mathrm{C}$ and $15 \mathrm{~L} / \mathrm{h}$. The protection factor (P.F.) was calculated as P.F. = (induction period with antioxidant)/(induction period without antioxidant). A protection factor greater than 1 indicates inhibition of the lipid oxidation. The higher the value, the better the antioxidant activity [16].

\section{Determination of malondialdehyde (MDA) by HPLC}

The determination of MDA was carried out after accelerated oxidation of sunflower oil under UV light according to the method reported by Tsaknis et al. [35]. Stripped sunflower oil (10 g, prepared using the method described by Fuster et al. [10]) and added antioxidant (pure extract, BHT, $\alpha$ tocopherol in concentrations of 100 and $150 \mathrm{ppm}$ ) were accurately weighed into a glass Petri dish (87 $\mathrm{mm}$ internal diameter and $15 \mathrm{~mm}$ in height) and mixed well. The dishes were placed (half immersed) in a water bath $\left(50{ }^{\circ} \mathrm{C}\right)$ directly exposed to UV light produced by a lamp situated $50 \mathrm{~cm}$ above (General Electric $260 \mathrm{~nm}$ UV Germicidal lamp G25T8, 25 Watt, $45 \mathrm{~cm}$ in length and $3 \mathrm{~cm}$ in diameter) for 12 hours. Then, the oils were stored in dark glass bottles with nitrogen and stored at -16 ${ }^{\circ} \mathrm{C}$ until analysis (MDA by HPLC) the same day. The method used for the determination of MDA was adapted from Tsaknis et al. [35]. HPLC was performed using a Waters System consisted of a Waters 
600E HPLC pump and Waters 486 Tunable Absorbance Detector (Millipore Corporation, Waters Chromatography Division, Massachusetts, MA 01757, USA). The mobile phase was $1 \%$ acetic acidacetonitrile $(85: 15, \mathrm{v} / \mathrm{v})$ and the flow rate was set at $2.5 \mathrm{~mL} / \mathrm{min}$. The retention time of MDA was 1.44 min.

\section{Preparation of liposomes}

The liposomes were prepared using a modification of the method described by Gortzi et al. [13], using common lipid composition [1], since as indicated by El Jastimi et al. [9], phosphatidylcholine/cholesterol liposomes show little leakage of contents. Liposomes containing egg L- $\alpha$-phosphatidylcholine (PC) (10 mg/mL) and cholesterol (C) $(2 \mathrm{mg} / \mathrm{mL})$ were prepared by the mechanical shaking technique (thin film method). PC and C were obtained from Sigma Chemicals Company Ltd. (St. Louis, USA). The $99 \%$ purity of the lipids was verified via thin-layer chromatography on silicic acid-coated plates (Merck, Darmstadt, Germany) as described previously [20]. The mixture of lipids was dissolved in chloroform-methanol $(3: 1,4 \mathrm{~mL})$ in a $50 \mathrm{~mL}$ roundbottom flask and the organic solvent was removed by rotary evaporator until a thin film was formed on the walls. When O. dictamnus extracts were used (in an amount of $1.6 \mathrm{mg} / \mathrm{mL}$ ) as antioxidant or antimicrobial agent, it was dissolved in methanol and then mixed in a round bottom flask with PC and C. The organic solvents were evaporated under a stream of nitrogen at $35{ }^{\circ} \mathrm{C}$ (above the lipid transition temperature). The lipid film was suspended in Phosphate Buffer Saline solution (PBS, $\mathrm{pH}=7.4,2 \mathrm{~mL}$, Sigma Chemicals Company Ltd., St. Louis, USA) and vigorously vortexed for $15 \mathrm{~min}$. Sonication of the preparation (in order to reduce the size and homogenize liposomes) was carried out in a Branson 125W bath-type sonicator (Branson Ultrasonics, Danbury, CT, USA). This suspension was allowed to hydrate for $2 \mathrm{~h}$ in the dark at room temperature (in order to anneal any structural defects) [1] and then centrifuged at 6,500 rpm at $4^{\circ} \mathrm{C}$ (using a Sorvall General-Purpose RC-3 Automatic Refrigerated Centrifuge, Ivan Sorvall INC., Newtown Connecticut, USA) in order to dispose no incorporated molecules of extracts or lipids from the liposome suspension. The supernatant of the centrifuged suspension was used to prepare multilamellar vesicles (MLV). When it was not possible to use the prepared liposomes the same day, they were freeze dried with a Virtis model, Sentry 5L (Virtis Company INC., Gardiner, New York, USA) in order to prevent storage problems [21].

\section{Liposome size determination}

The method used was adapted from Gortzi et al. [13]. A total of $50 \mathrm{~mL}$ of the liposome dispersion were diluted with $20 \mathrm{~mL}$ of filtered PBS (through $0.22 \mathrm{~mm}$ pore size, polycarbonate filters, Millipore, UK) and the size was immediately determined by photon correlation spectroscopy using a Malvern 4700C (Malvern Instruments Ltd., Malvern, Worcestershire, UK), which enabled the mass distribution of particle size to be obtained, according to manufacturer. Measurements were made at $25{ }^{\circ} \mathrm{C}$ with a fixed angle of $90^{\circ}$ and sizes quoted are the z-average mean (dz) for the liposomal hydrodynamic diameter. The size of liposomes was also confirmed by image analysis of electron micrographs using a Leica Q500MC image analysis system (Leica Cambridge Ltd, Cambridge, UK). 


\section{Liposomal surface charge}

The method used was adapted from Gortzi et al. [13]. Liposome dispersions were diluted with PBS (pH 7.4) and their electrophoretic mobility was measured at $25^{\circ} \mathrm{C}$ by photon correlation spectroscopy (Zetasizer 5000, Malvern Instruments Ltd., UK). Zeta potentials of the dispersions were calculated by the instrument according to the Smolowkovski equation.

\section{Differential Scanning Calorimetry (DSC)}

The extracts were encapsulated in liposomes and their antioxidant action was again estimated using DSC. A Perkin Elmer DSC-6 calorimeter (Perkin Elmer Corp., Norwalk, CT, USA) was employed to study the oxidation stability of the samples according to the method described by Gortzi et al. [13]. Samples (4 mg) were placed in DSC aluminum crucibles closed with lids perforated by a hole (internal diameter: $1 \mathrm{~mm}$ ) in the centre in order to allow the sample to be in contact with the oxygen stream. The purge gas foaming the reaction atmosphere was oxygen. An empty crucible, hermetically sealed, was used as reference. The starting temperature of oxidation was determined as the onset temperature of the oxidation peak. The temperature program was: heat from $30{ }^{\circ} \mathrm{C}$ to $180{ }^{\circ} \mathrm{C}\left(100{ }^{\circ} \mathrm{C} / \mathrm{min}\right)$, hold for $1 \mathrm{~min}$ at $180^{\circ} \mathrm{C}$ and finally heat from $180^{\circ} \mathrm{C}$ to $370{ }^{\circ} \mathrm{C}\left(10^{\circ} \mathrm{C} / \mathrm{min}\right)$.

\section{Antimicrobial bioassay}

The antibacterial activity of the methanol extract was determined, using the diffusion technique of Bauer-Kirby (disc method) [3] according to Gortzi et al. [13], by measuring the zone of inhibition against four Gram positive bacteria: Staphylococcus aureus (ATCC 25923), Staphylococcus epidermidis (ATCC 12228), Staphylococcus mutans (ATCC 31989) and Staphylococcus viridans (ATCC 19952), and four Gram negative: Pseudomonas aeruginosa (ATCC 27853), Escherichia coli (ATCC 25922), Enterobacter cloacae (ATCC 13047) and Klebsiella pneumoniae (ATCC 13883), as well as against three human pathogenic fungi Candida albicans (ATCC 10231), Candida tropicalis (ATCC 13801) and Candida glabrata (ATCC 28838) and finally, against the food-pathogen bacteria of Listeria monocytogenes. Standard antibiotics netilmicin and intraconazole (both from Sanofi, Diagnostics Pasteur, Paris, France) were used in order to control the sensitivity of the tested bacteria and fungi, respectively. The tested compounds were dissolved in methanol. For each experiment a control disc with pure solvent and a disc with empty liposomes (phosphatidylcholine:cholesterol 10:2 $\mathrm{mg} / \mathrm{mL}$ ) was used as blind control. All the paper discs had a diameter of $6 \mathrm{~mm}$ and were deposited on the surface of the seeded trypticase soy agar (Scharlau Chemi S.A., Barcelona, Spain) Petri dishes. Six $\mu \mathrm{l}$ of a solution of $1 \mathrm{mg} / \mathrm{mL}$ of the extracts have been put on the discs. The plates were inoculated with the tested organisms to give a final cell concentration of $10^{7} \mathrm{CFU} / \mathrm{mL}$ and incubated for $48 \mathrm{~h}$ at $37^{\circ} \mathrm{C}$. The fungi were grown on Sabouraud's agar (Pronadisa, Conda Lab., Madrid, Spain) at $25^{\circ} \mathrm{C}$ for $48 \mathrm{~h}$. The results were expressed as mm of zone of inhibition. 
Statistical analysis

Results were expressed as the means and standard deviation (SD in parenthesis) of three simultaneous assays carried out in all methods. Statistical significance of the differences between mean values was assessed by ANOVA test.

\section{Acknowledgements}

This study has been co-funded by the European Union (75\%) and the Greek Government (25\%) within the framework of the Education and Initial Vocational Training Program - EPEAEK I Archimedes.

\section{References and Notes}

1. Abdalla, A. E.; Roozen, J. P. The effects of stabilised extracts of sage and oregano on the oxidation of salad dressings. Europ. Food Res. Technol. 2001, 212, 551-560.

2. Azaizeh, H.; Ljubuncic, P.; Portnaya, I.; Said, O.; Cogan, U.; Bomzon, A. Fertilization-induced changes in growth parameters and antioxidant activity of medicinal plants used in traditional Arab medicine. Evid. Based Complement. Alternat. Med. 2005, 2, 549-556.

3. Bauer, A. W.; Kirby, W. M. M.; Sherris, J. C.; Turcu, M. Antibiotic Susceptibility Testing by a Standardized Single Disk Method. Am. J. Clin. Pathol. 1966, 45, 493-496.

4. Baeumner, A.; Caroline, J.; Ching, W.; Andrew, P. A generic sandwich-type biosensor with nanomolar detection limits. Anal. Bioanal. Chem. 2004, 378, 1587-1593.

5. Chang, S. S.; Ostric-Matijasevic, B.; Hsieh, O. A. L.; Huang, C. L. Natural antioxidants from rosemary and sage. J. Food Sci. 1977, 42, 1102-1106.

6. Conforti, F.; Statti, G.; Uzunov, D.; Menichini, F. Comparative chemical composition and antioxidant activities of wild and cultivated Laurus nobilis L. leaves and Foeniculum vulgare subsp. piperitum (Ucria) Coutinho seeds. Biol. Pharm. Bull. 2006, 29, 2056-2064.

7. Couladis, M.; Tzakou, O.; Verykokidou, E.; Harvala, C. Screening of some Greek aromatic plants for antioxidant activity. Phytother. Res. 2003, 17, 194-195.

8. Economou, K. D.; Oreopoulon, V.; Thomopoulus, C. D. Antioxidative activity of some plants of the family Labiatae. J. Am. Oil Chem. Soc. 1991, 68, 109-113.

9. El Jastimi, R.; Edwards, K.; Lafleur, M. Characterization of permeability and morphological perturbations induced by nisin on phosphatidylcholine membranes. Biophys. J. 1999, 77, 842-852.

10. Fuster, M. D.; Lampi, A. M.; Hopia, A.; Kamal-Eldin, A. Effects of $\alpha$ - and $\gamma$-tocopherols on the autoxidation of purified sunflower triacylglycerols. Lipids 1998, 33, 715-722.

11. Gergis, V.; Spiliotis, V.; Poulos, C. Antimicrobial activity of essential oils from Greek Sideritis species. Pharmazie 1990, 45, 70-71.

12. Gibbs, B. F.; Kermasha, S.; Alli, I.; Mulligan, C. N. Encapsulation in Food industry: a review. Int. J. Food Sci. Nutr. 1999, 50, 213-24.

13. Gortzi, O.; Lalas, S.; Chinou, I.; Tsaknis, J. Reevaluation of antimicrobial and antioxidant activity of Thymus spp. extracts before and after encapsulation in liposomes. J. Food Protect. 2006, 69, 2998-3005. 
14. Gortzi, O.; Lalas, S.; Chinou, I.; Tsaknis, J. Reevaluation of bioactivity and antioxidant activity of Myrtus communis extract before and after encapsulation in liposomes. Eur. Food Res. Technol. 2007, accepted for publication.

15. Lagouri, V.; Boskou, D. Nutrient antioxidants in Oregano. Int. J. Food Sci. Nutr. 1996, 47, 493497.

16. Lalas, S.; Dourtoglou, V. Use of rosemary extract in preventing oxidation during deep fat frying of potato chips. J. Am. Oil Chem. Soc. 2003, 80, 579-583.

17. Lawrence, S. M.; Alpar, H. O.; McAllister, S. M.; Brown, M. R. W. Liposomal (MLV) polymyxin B, physiochemical characterization and effect of surface charge on drug association. J. Drug Targ. 1993, 1, 303-310.

18. Litwinienko, G.; Kasprzycka-Guttman, T.; Studzinski, M. Effects of selected phenol derivatives on the autoxidation of linolenic acid investigated by DSC non-isothermal methods. Thermochim. Acta 1997, 331, 97-106.

19. Moller, J. K. S.; Madsen, H. L.; Aaltonen, T.; Skibsted, L. H. Dittany (Origanum dictamnus) as a source of water-extractable antioxidants. Food Chem. 1999, 64, 215-219.

20. New, R.R.C. Liposomes-a practical approach; Oxford University Press; New York, 1990; pp. 109-111.

21. Özer, Y.; Talsma, H.; Crommelin, D. J. A.; Hical, A. A. Influence of freezing and freeze-drying on the stability of liposomes dispersed in aqueous media. Acta Pharm. Technol. 1988, 34, 129139.

22. Panizzi, L.; Flamini, G.; Cioni, P. L.; Morelli, I. Composition and antimicrobial properties of essential oils of four Mediterranean Lamiaceae., J. Ethnopharmacol. 1993, 39, 67-170.

23. Pellecuer, J.; Jacob, M.; Simeon de Buechberg, M.; Allegrini, J. Therapeutic value of the cultivated mountain savory (Satureia montana L.: Labiatae). Acta Hort. 1980, 96, 35-39.

24. Sachetelli, S.; Khalil, H.; Chen, T.; Beaulac, C.; Senechal, S.; Lagace, J. Demonstration of a fusion mechanism between a fluid bactericidal liposomal formulation and bacterial cells. Biochim. Biophys. Acta 2000, 1463, 254-266.

25. Shoji, Y.; Nakashima, H. Nutraceutics and delivery Systems. J. Drug Target. 2004, 12, 385-391.

26. Sivropoulou, A.; Kokkini, S.; Lanaras, T.; Arsenakis, M. Antimicrobial activity of mint essential oils. J. Agr. Food Chem. 1995, 43, 2384-2388.

27. Skaltsa, H.; Harvala, C. Contribution a l'etude Chimique d' Origanum dictamnus L. - $1^{\text {re }}$ Communication (Glucosides des Feuilles). Plant. Méd. Phytothér. 1986, 4, 300-304.

28. Skaltsa, H.; Harvala, C. Contribution a l'etude Chimique d' Origanum dictamnus L. $-2^{\text {nd }}$ Communication (Glucosides des Feuilles). Plant. Méd. Phytothér. 1987, 1, 56-62.

29. Stamatis, G.; Kyriazopoulos, P.; Golegou, S.; Basayiannis, A.; Skaltsas, S.; Skaltsa, H. In vitro anti-Helicobacter pylori activity of Greek herbal medicines. J. Ethnopharmacol. 2003, 88, 175179.

30. Sułkowski, W. W.; Pentak, D.; Nowak, K.; Sułkowska, A. The influence of temperature, cholesterol content and pH on liposome stability. J. Mol. Struct. 2005, 744-747, 737-747.

31. Taylor, M.; Davidson, M.; Bruce, B.; Weiss, J. Liposomal Nanocapsules in food Science and agriculture. Crit. Rev. Food Sci. 2005, 45, 587-605. 
32. Tepe, B.; Daferera, D.; Sökmen, M.; Polissiou, M.; Sökmen, A. In Vitro Antimicrobial and Antioxidant Activities of the Essential Oils and Various Extracts of Thymus eigii M. Zohary et P.H. Davis. J. Agr. Food Chem. 2004, 52, 1132-1137.

33. Thanos, C. A. In Plant-animal interactions in Mediterranean-Type ecosystems; Arianoutsou, M.; Groves, R. H., Eds.; Kluwer Academic Publishers: Dordrect, The Netherlands, 1994; pp. 3-11.

34. Tsaknis, J; Lalas, S. Extraction and identification of natural antioxidant from Sideritis euboea (mountain tea). J. Agric. Food Chem. 2005, 53, 6375-6381.

35. Tsaknis, J.; Hole, M.; Smith, G.; Lalas, S.; Tychopoulos, V. An HPLC rapid method of determining malondialdehyde (MDA) for evaluation of rancidity in edible oils. Analyst 1998, 123, 325-327.

36. Velasco, J.; Andersen, M. L.; Skibsted, L. H. Evaluation of oxidative stability of vegetable oils by monitoring the tendency to radical formation. A comparison of electron spin resonance spectroscopy with the Rancimat method and differential scanning calorimetry. Food Chem. 2004, 85, 623-632.

Sample Availability: Available from the authors.

(c) 2007 by MDPI (http://www.mdpi.org). Reproduction is permitted for noncommercial purposes. 